\title{
Facial Recess Relations
}

Alaa A. Abou-Bieh, MD

Department of Otolaryngology, Faculty of

Medicine, Mansoura University, Mansou-

ra, Egypt

\begin{abstract}
Objectives: (1) Describe the relations of the facial recess (FR) to the sinus tympani (ST), posterior tympanic sinus (PTS), lateral tympanic sinus (LTS), mastoid segment of the facial nerve (FN), and stapedius muscle (STM) based on their otoendoscopic, surgical, and radiologic anatomy and in relation to their development theories. (2) Evaluate the possible surgical approaches.

Methods: Fifty-five temporal bones were dissected, and the anatomic details were studied utilizing an operating microscope and otoendoscopes of different angles. In addition, the recesses anatomy and relations were studied in 200 temporal bones computed tomography scans.

Results: The retrotympanic recesses pneumatization could be classified as axial (FR) and sagittal (ST, PTS, and LTS). The 3 sagittal recesses showed fixed relations to each other, with ST and PTS medially (superiorly and inferiorly, respectively) and LTS laterally. FR inlet located superolateral to the other sinuses while the recess itself extended laterally $(44 \%)$ and posteriorly $(20 \%)$ to them and in relation to the FN and SM. When ST was extensively pneumatized, it showed a direct relation with the FR extension posterior to the FN. Although it was possible to approach all 4 recesses endoscopically via the transcanal route, it was necessary to approach FR and ST via combined transcanal and transmastoid approaches when they were extensively pneumatized posteriorly and laterally.

Conclusions: Relations between the FR and the retrotympanic structures are significantly variable and influenced mainly by the type and extent of the pneumatization. Extensively or unusually pneumatized types need special or combined approaches.
\end{abstract}

\section{Introduction}

The aim of this study is to describe the relations of the facial recess (FR) to the other retrotympanic recesses, the sinus tympani (ST), the posterior tympanic sinus (PTS) and the lateral tympanic sinus (LTS) and to the mastoid segment of the facial nerve (FN), and stapedius muscle (STM). Also, is to describe the relations of the four retrotympanic recesses to each other. This would be based on the otoendoscopic, surgical microscopic and radiologic anatomy and in relation to the development and pneumatization theories. In addition, to evaluate the facial recess (FR) and the other retrotympanic recesses possible surgical approaches.

\section{Material and Methods}

The gross anatomy and anatomical variations of posterior mesotympanum and retrotympanic areas including the facial recess (FR) and the other retrotympanic recesses were studied in 55 Fresh frozen temporal bones (TBs). To the best of our knowledge, all bones came from adult cadavers. There were 31 right temporal bones and 24 left. All bones were dissected by the same approach and all were studied utilizing an operating microscope and otoendoscopes with 00,300 and 700 angles and 2.7 and $3 \mathrm{~mm}$ diameters. In addition, the recesses anatomy and relations were studied in two hundred temporal bones CT scans $(=400$ sides). These scans were randomly chosen re- 
gard less they were of normal individuals or showing any type of temporal bone pathology, but all were for adults.

\section{Results}

To better study the recesses pneumatization it is important to describe them according to their main 2D plane of pneumatization according to the point with maximum diameter.

The facial recess (FR) could be better described as an axially oriented recess with or without extension in the coronal direction while the sinus tympani (ST), lateral tympanic sinus (LTS) and posterior tympanic sinus (PTS) were sagittally oriented recesses.

The sinus tympani (ST), the lateral tympanic sinus (LTS) and the posterior tympanic sinus (PTS) were all located in the petrous bone (pTB), medial to the squmous bone (sTB) and koronors septum (KS), lateral to the laberynthine bone (ITB) and above and around the styloid bone (sTB).

The facial recess (FR) was located in the squmous bone (sTB) either medial to koronors septum (KS) or the septum (KS) was ending in the recess posterior bony cover.
The three sagittal recesses showed fixed relations to each other with the sinus tympani (ST) inferiorly, the posterior tympanic sinus (PTS) superiorly and the lateral tympanic sinus (LTS) laterally.

The facial recess (FR) inlet could be located always superolateral to the other three sinuses.

The facial recess (FR) extended laterally to the other three recesses and in relation to the mastoid segment of the Facial nerve (FN) in $44 \%$ of the temporal bones specimens (TB).

The facial recess (FR) extended Posteriorly to the other three recesses and in relation to the mastoid segment of the Facial nerve (FN) in $20 \%$ of the temporal bones specimens (TB).

When the sinus tympani (ST) was extensively pneumatized, it showed a direct relation with the facial recess (FR) extension posterior to the Facial Nerve (FN).

Although it was possible to approach all the four recesses endoscopically via the trans-canal route, it was necessary to approach the facial recess (FR) and the sinus tympani (ST) via combined trans-canal and trans-mastoid approaches when they were extensively pneumatized. 

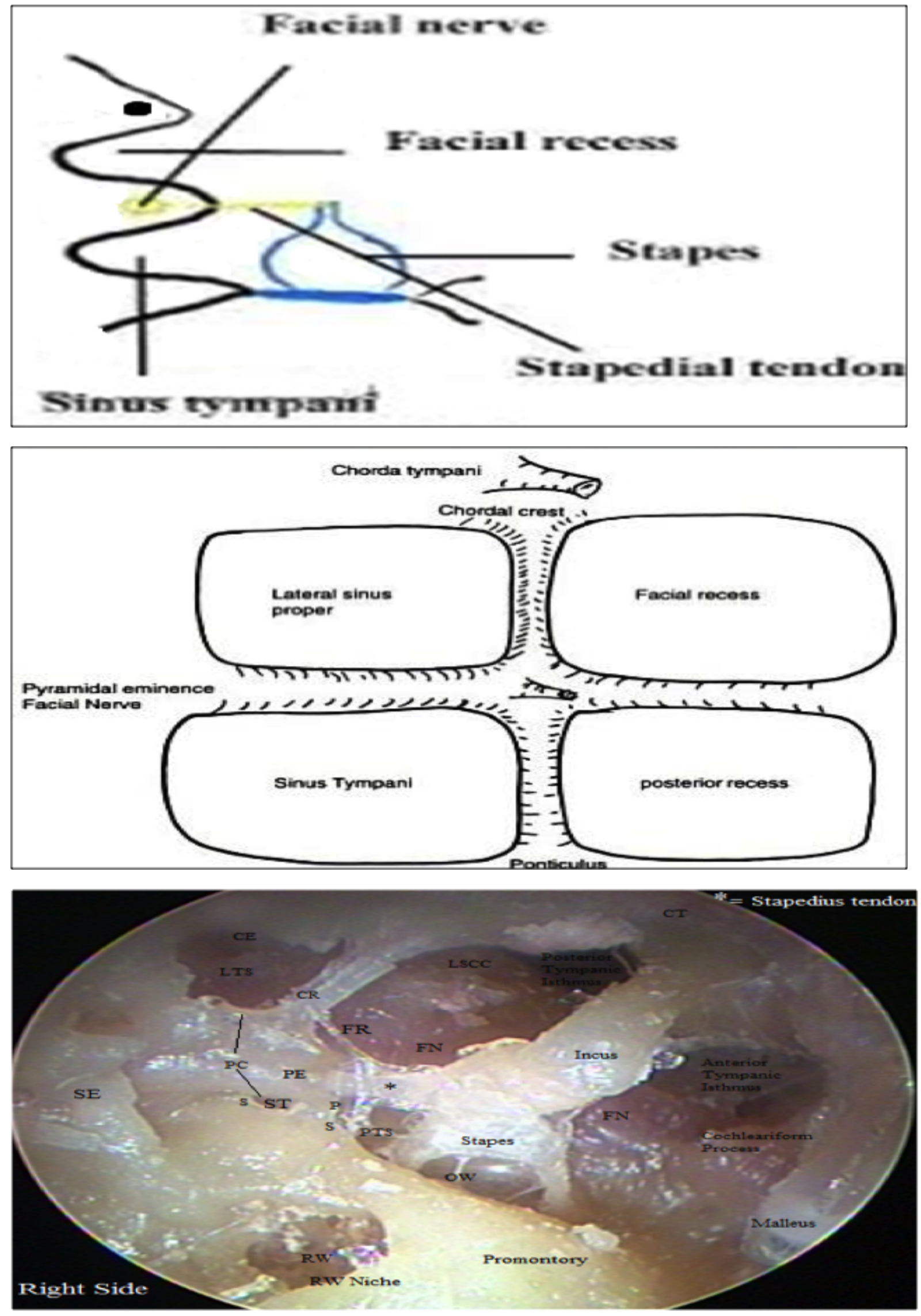

2016 Mansoura Medical Journal 
Atorvastatin and metformin in MetS Alaa A. Abou-Bieh, MD 66
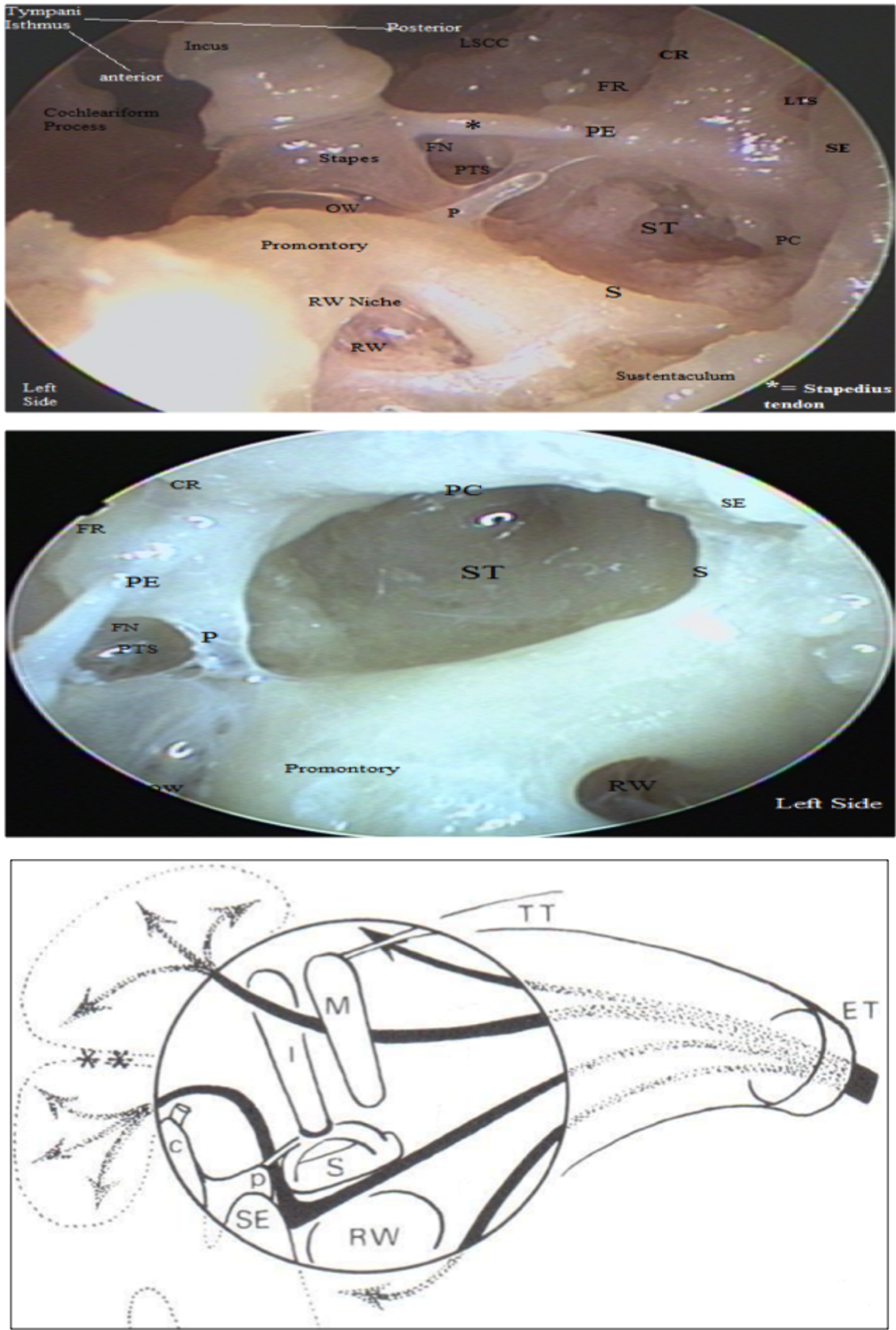

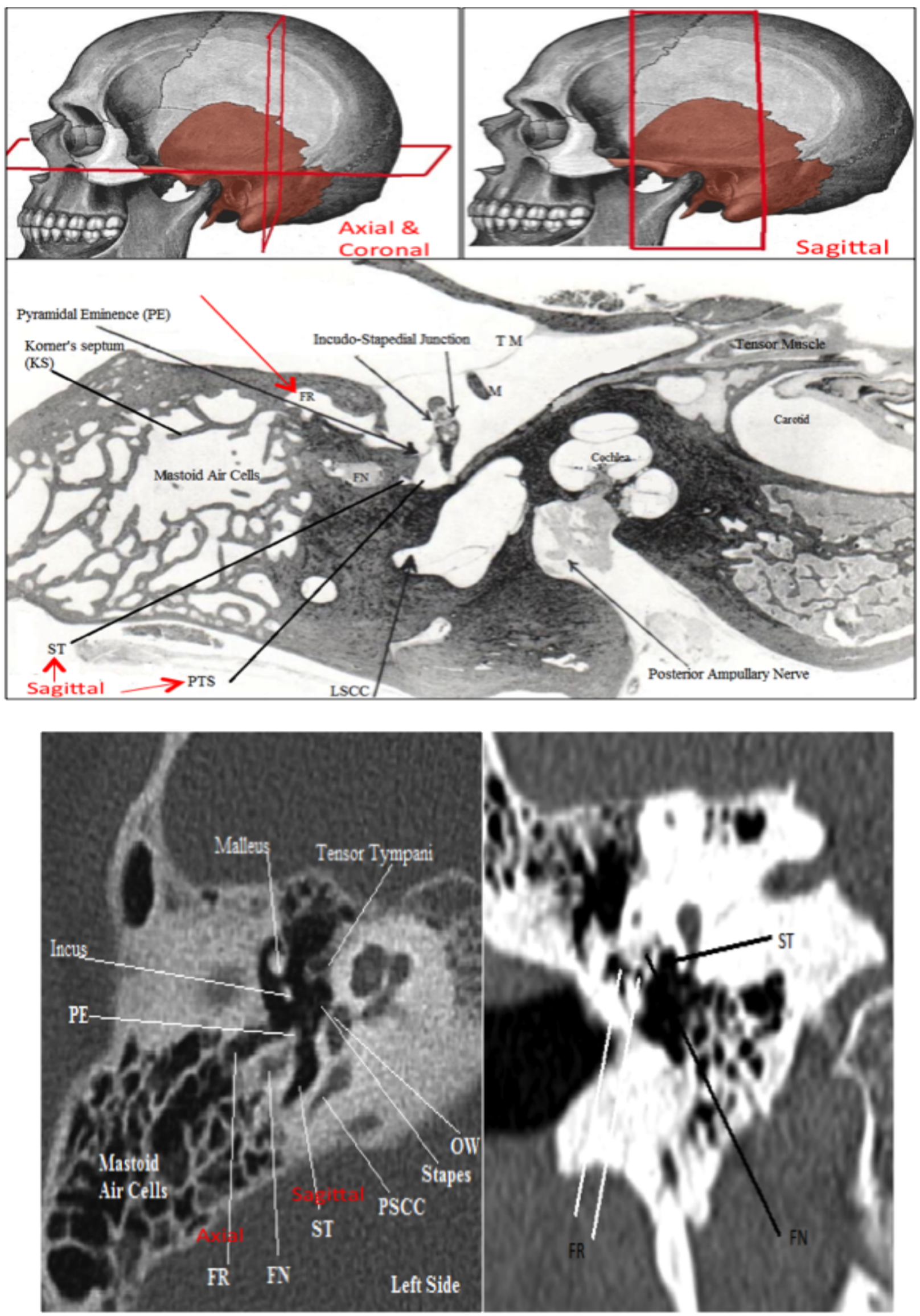
Atorvastatin and metformin in MetS Alaa A. Abou-Bieh, MD 68

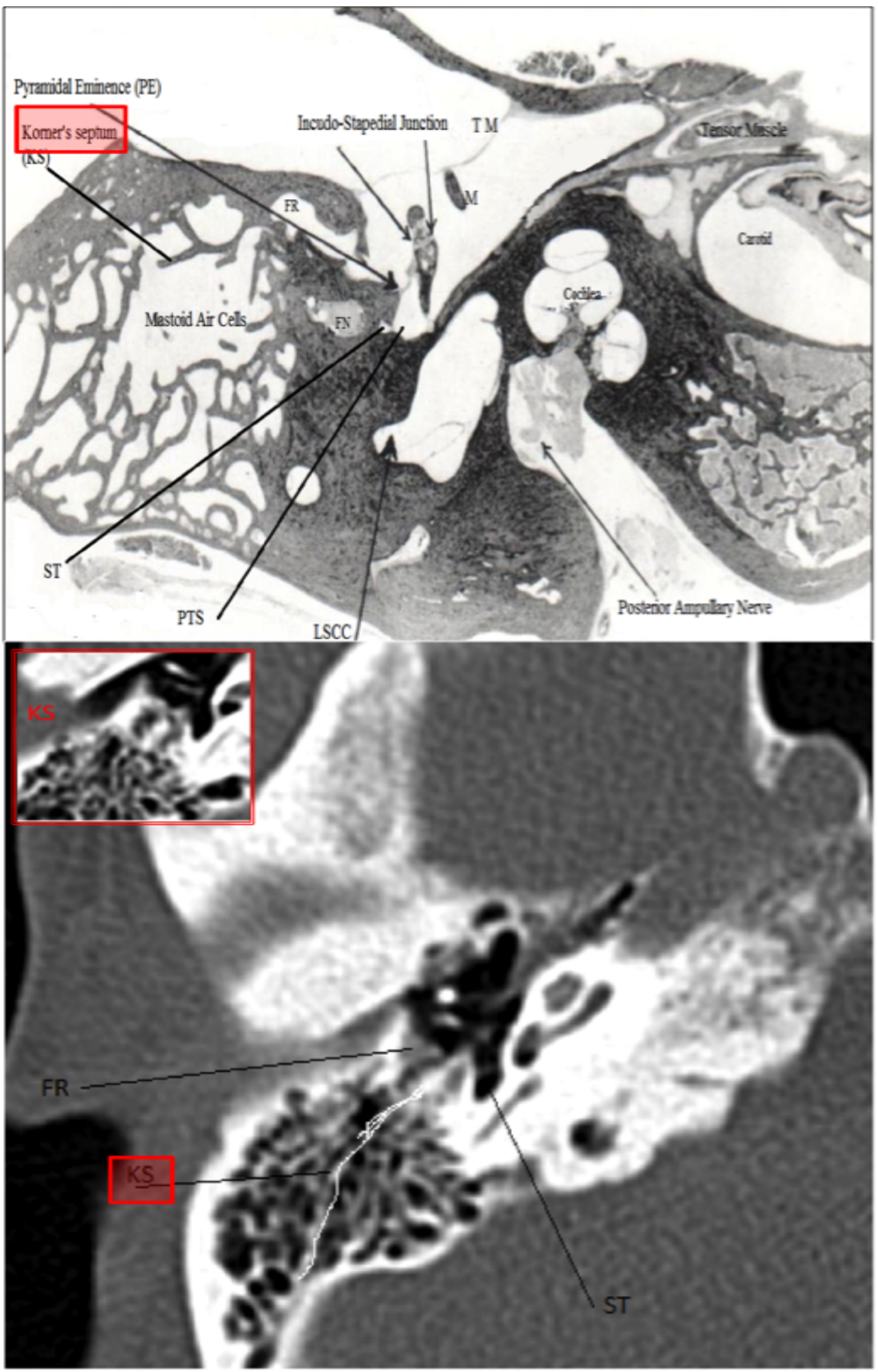




\section{Discussion}

The retrotympanum has four recesses, facial recess (FR), lateral tympanic sinus proper (LTS), sinus tympani (ST) and posterior tympanic sinus (PTS). ${ }^{1}$ Authors usually classify the recesses according to their relations to the facial nerve canal (FN) into Lateral recesses and medial recesses with the facial recess (FR) lateral and superior, the lateral tympanic sinus proper (LTS) lateral and inferior, the posterior tympanic sinus (PTS) medial and superior and the sinus tympani (ST) medial and inferior. ${ }^{1-3}$

The facial recess (FR) is mainly bounded medially by the mastoid segment of the facial nerve (FN), superiorly by the incus buttress (In) and laterally by the annulus (An) or the chorda tympani (CT). The lateral tympanic sinus (LTS) is mainly bounded medially by the facial nerve (FN) and the pyramidal crest $(P C)$, superiorly by the pyramidal Eminence (PE) and the chordal ridge (CR), laterally the chordal eminence (CE) and inferiorly by the styloid eminence (SE). The posterior tympanic sinus (PTS) is mainly bounded medially by the oval window (OW), superiorly by the tympanic segment of facial canal (tFN), laterally by the facial nerve (FN) and the pyramidal crest (PC) and inferiorly by the ponticulus ( $\mathrm{Po})$. The sinus tympani (ST) is mainly bounded medially by the promontory (Pro), superiorly by the ponticulus (Po), inferiorly by the subiculum (Su) and laterally by the pyramidal crest (PC). 1

The recesses are formed by the abutting of the primitive endothelial pouches of the eustachian tube (ET) origin as they develop the middle ear (ME) air cell system against the solid upper portion of the Reichert's cartilage of the second branchial arch which ossifies to develop the styloid complex of the Posterior tympanic wall and already ossified lateral semicircular canal (otic capsule) (LSCC) around the developing facial nerve
(FN). 1 The facial recess (FR) develops from the saccus superior which ascends over the styloid complex through the posterior tympanic isthmus (PTI) to form the squamosal portion of the mastoid. The sinus tympani (ST), the posterior tympanic sinus (PTS) and the lateral tympanic sinus (LTS) develop from the saccus posticus which forms the hypotympanum (HyT), the round window niche $(R W)$ and the inferior half of the oval window niche (OW).

After birth and during childhood, the neck grows at a more rapid pace compared to the skull, so that the inferior portion of the tympanic membrane (TM) rotates outward, enlarging the hypotympanum (HyT) while the mastoid is pulled down and out by the growth of the sternomastoid muscle which facilitates the expansion of the endotheliallined pouchs originating from the primitive eustachian tube (ET) into the middle ear cleft.

The published data about the detailed anatomy of the retrotympanic recesses has three peaks, the microscope era, the CT scans era and the endoscopes era. Recently, many articles described detailed anatomy of the facial recess and sinus tympani and classified their types based on different criteria. Yet no work was published to describe the detailed relations of the recesses to each other.

conclusion:

The relations between the facial recess (FR) and retrotympanic recesses and also the relations between the recesses and each other are variable. These relations depend mainly on the type and extent of their pneumatization which are the main determine the anatomical relations between the structures in the retro-tympanic area.

Extensively or unusually pneumatized types of the recesses need special or combined approaches. 


\section{References}

1. Proctor B. Surgical anatomy of the posterior tympanum. Ann Otol Rhinol Laryngol 1969;78:1026-40.

2. Marchioni $D$, Alicandri-Ciufelli M, Piccinini $A$, et al. Inferior retrotympanum revisited: an endoscopic anatomic study. Laryngoscope 2010;120(9):1880-6.

3. Amjad AH, Starke JJ, Scheer AA. Tympanofacial recess in the human ear. Arch Otolaryngol 1968 Aug;88(2):131-7.

4. Young YS, Nadol JB Jr. Dimensions of the extended facial recess. Ann Otol Rhinol Laryngol 1989 May;98(5 Pt 1):336-8.

5. Messerotti G, Ghibellini MD, Rinaldi Ceroni A. Some anatomical remarks on the posterior region of the tympanic cavity. Boll Soc Ital Biol Sper 1993 Jun;69(6):357-63.

6. Steinbrugge H. On sinus tympani. Arch Otolaryngol 1889;8:53-7.

7. Danaldson JA, Anson BJ, Warpeha RL, et al. The surgical anatomy of the sinus tympani. Arch Otolaryngol Head Neck Surg 1970;91:219-27.

8. Saito R, Igarashi M, Alford BR, et al. Anatomical measurement of the sinus tympani. Arch Otolaryngol Head Neck Surg 1971;94:418-25.

9. Pickett BP, Cail WS, Lambert PR. Sinus tympani: anatomic considerations, computed tomography, and a discussion of the retro-facial approach for removal of disease. Am J Otol 1995;16:741-50.

10. Eby TL. Development of the facial recess: implications for cochlear implantation. Laryngo-
11. Chen B, Yin S, Shen P. The Feasibility of the Retrofacial Approach to the Pediatric Sinus Tympani. Otolaryngol Head Neck Surg 2005;133:780-5.

12. Bielamowicz SA, Coker NJ, Jenkins HA, Igarashi $M$. Surgical dimensions of the facial recess in adults and children. Arch Otolaryngol Head Neck Surg 1988 May;114(5):534-7.

13. McRackan TR, Reda FA, Rivas A, Noble JH, Dietrich MS, Dawant BM, Labadie RF. Comparison of cochlear implant relevant anatomy in children versus adults. Otol Neurotol 2012 Apr;33(3):328-34.

14. Dahm MC, Shepherd RK, Clark GM. The postnatal growth of the temporal bone and its implications for cochlear implantation in children. Acta Otolaryngol Suppl 1993;505:1-39.

15. Parlier-Cuau C, Champsaur P, Perrin E, Rabischong $\mathrm{P}$, Lassau JP. High-resolution computed tomographic study of the retrotympanum. Anatomic correlations. Surg Radiol Anat 1998;20(3):215-20.

16. MeKennan KX. Endoscopic 'second look' mastoidoscopy to rule out residual epitympnic/ mastoid cholesteatoma. Laryngoscope 1993;103:810-4.

17. Marchioni D, Mattioli F, Alicandri-Ciufelli M, et al. Transcanal endoscopic approach to the sinus tympani: a clinical report. Otol Neurotol 2009;30(6):758-65.

18. Jiang H, Zhang J, Wen S. Endoscopic anatomy of the middle ear. Lin Chuang Er Bi Yan Hou Ke Za Zhi 2002 Jan;16(1):17-8.

19. Hamamoto M, Himi T, Murakami G. Surgical 
anatomy of the facial nerve and chorda tympani with special reference to cochlear implantation. Nihon Jibiinkoka Gakkai Kaiho 1999 Jun;102(6):825-34.

20. Hamamoto M, Murakami G, Kataura A. Topographical relationships among the facial nerve, chorda tympani nerve and round window with special reference to the approach route for cochlear implant surgery. Clin Anat 2000;13 (4):251-6.

21. Bettman RH, Appelman AM, van Olphen AF, Zonneveld FW, Huizing EH. Cochlear orientation and dimensions of the facial recess in cochlear implantation. ORL J Otorhinolaryngol Relat Spec 2003 Nov-Dec;65(6):353-8.

22. He X, Feng Y, Chen D, Mei L, He C, Cai X. Study of the anatomy related to cochlear implantation guided by HRCT. Lin Chung $\mathrm{Er} \mathrm{Bi}$ Yan Hou Tou Jing Wai Ke Za Zhi 2011 May;25(10):433-5.

23. Jeon EJ, Jun B, Song JN, Kim JE, Lee DH, Chang $\mathrm{KH}$. Surgical and radiologic anatomy of a cochleostomy produced via posterior tympanotomy for cochlear implantation based on three-dimensional reconstructed temporal bone CT images. Surg Radiol Anat 2013 Aug;35(6):471-5.

24. Cheita AC, M_ru N, Mogoanta CA, lonita E. The recesses of the retro-tympanum. Rom $\mathrm{J}$ Morphol Embryol 2010;51(1):61-8.

25. Wang H, Shan X, Meng Z, Sun H, Zhao L. Anatomical measurements and clinical applications through facial recess approach. Lin Chung Er Bi Yan Hou Tou Jing Wai Ke Za Zhi 2013 Jul;27(13):708-11.

26. Ozturan O, Bauer C, Miller C, et al. Dimensions of the sinus tympani and its surgical access via a retrofacial approach. Ann Otol Rhinol Laryngol 1996;105:776-83.

27. Jackson CG. The infratympanic extended facial recess approach for anteriorly extensive middle ear disease: a conservation technique. Laryngoscope 1993 Apr;103(4 Pt 1):451-4.

28. Rizk H, O'Connell B, Stevens S, Meyer T. Retrofacial approach to access the round window for cochlear implantation of malformed ears. Otol Neurotol 2015 Mar;36(3):e79-83.

29. Jasen $C$. The combined approach for tympanoplasty. J Laryngol Otol 1968;82:779-93. 